\title{
Valuing Disease Prevention in a Vegetatively Propagated Annual Crop: Benefits From the Montana Seed Potato Certification Program
}

\author{
Kate Binzen Fuller, ${ }^{1, \dagger}$ Christopher McIntosh, ${ }^{2}$ and Nina Zidack $^{3}$ \\ ${ }^{1}$ Department of Agricultural Economics and Economics and Montana State University Extension, Montana State University, \\ Bozeman, MT 59717 \\ ${ }^{2}$ Department of Agricultural Economics and Rural Sociology, University of Idaho, Moscow, ID 83844 \\ ${ }^{3}$ Montana Seed Potato Certification Program, Montana State University, Bozeman, MT 59717
}

\begin{abstract}
We examine the economic costs of potato virus Y (PVY) and benefits to commercial potato growers from using screened seed. To do so, we use a quantile regression model to explore disease spread. We use this model to predict disease prevalence and corresponding losses in commercial potato operations with and without a screening and certification

amount of PVY in the seed can have major effects on commercial potato grower revenues and profitability. Using data and models from Idaho, a major purchaser of Montana seed, we estimate the annual benefit from Montana's program to Idaho to average \$205 per acre or \$22 million for the state.
\end{abstract} program in place. Our analysis suggests that this screening is very important; the amount of PVY in seed in the summer test is the strongest predictor of PVY in the winter test of the variables in our model. The
Keywords: disease management, Montana seed potatoes, potato virus Y, PVY, viruses and viroids, yield loss and economic impacts
Potatoes are the leading vegetable crop produced in the United States in terms of farmgate value. Because potatoes are grown from potato tuber pieces rather than true seed, they are susceptible to a number of tuberborne diseases. One of the most prevalent potato diseases is potato virus Y (PVY). PVY causes mosaic, foliar necrosis and occasionally, tuber necrosis, and it results in reductions in yields and quality. It is responsible for many rejections of seed lots and reduces crop value (Gray et al. 2010). As a result, it is one of the main reasons why seed potato screening and certification programs exist. In this paper, we estimate costs from PVY and the benefits from one potato disease screening and certification program.

PVY is a potyvirus, the largest of the plant virus groups, and it is thought to be one of the most destructive families of plant viruses affecting potatoes (Ivanov et al. 2014). Symptoms of PVY can vary greatly across potato varieties, and there are numerous strains that vary significantly in disease expression. Disease symptoms may be absent in some cultivars and can range from very mild to plant death depending on cultivar and strain interaction (Gray et al. 2010; Green et al. 2017; Nolte et al. 2009). Other effects include decreases in tuber size and tuber necrosis (Nolte et al. 2009). Resulting yield losses for plants grown from infected seed vary dramatically. Hane and Hamm (1999) found that total yields were reduced by 29 to $79 \%$ depending on the

${ }^{\dagger}$ Corresponding author: K. B. Fuller; kate.fuller@montana.edu

Funding: This research was funded in part by U.S. Department of Agriculture National Institute of Food and Agriculture grants Hatch Multi-State Project 1011710 and SCRI 2014-5118-22373 and Montana Department of Agriculture grant Specialty Crop Block Grant 16SC0005006.

*The $\boldsymbol{e}$-Xtra logo stands for "electronic extra" and indicates that one supplementary table is published online.

The author(s) declare no conflict of interest.

Accepted for publication 22 February 2020

Copyright $(9) 2020$ The Author(s). This is an open access article distributed under the CC BY-NC-ND 4.0 International license. potato variety. Whitworth et al. (2006) found reductions in total yield ranging from 38 to $63 \%$ based on soil nitrogen levels and potato variety. Other studies (Nolte et al. 2009) have investigated the role of spread over the season in determining end losses when the seed planted is infected at $<100 \%$ levels. In 2009 and 2013, concern over visual detection has been raised after new strains of PVY that show few foliar symptoms but still cause tuber necrosis have made their way into North America (Karasev and Gray 2013; Nolte et al. 2009).

PVY is mainly transmitted by aphids, and it can be acquired from an infected plant and transmitted to a healthy plant within seconds. PVY is a nonpersistent virus, and it is retained for $<12 \mathrm{~h}$ in aphid vectors (Moury et al. 2007). PVY can also be transmitted by contaminated machinery and tools or by damaging plants while walking through the field (Coutts and Jones 2015; German 2001; MacKenzie et al. 2018a, b).

Because PVY is a nonpersistent virus with extremely quick acquisition and potential transmission, insecticides are generally ineffective in controlling spread. Even in the presence of insecticides, aphids can move from an infected plant to a healthy plant and transmit the virus before they die. Crop oils have been more successful because they provide a physical barrier to stylet penetration (MacKenzie et al. 2014). The most effective method of controlling PVY remains planting seed potatoes certified to have low or no detectable virus. Additional management practices include reducing mechanical spread by sanitizing equipment and limiting field traffic, rogueing (removing) symptomatic plants, controlling "volunteer" potatoes, planting crop borders, and killing potato vines earlier in the growing season (German 2001; Nolte et al. 2009).

Potato production. In 2016, U.S. potato production resulted in $\$ 3.74$ billion in sales. Most potatoes are processed to make potato chips, French fries, dehydrated potatoes, and other products. Others are sold fresh or sold as seed, and a very small percentage is used as feed for farm animals (USDA Economics, Statistics, and Market Information System [ESMIS] 2017).

In this analysis, we examine potato production in Idaho with seed produced in Montana. Idaho is the number 1 potato-producing U.S. state in terms of volume of potatoes produced, and a large portion of the seed potatoes planted there originates in Montana. Figure 1 shows potato acreage, production, and yield over time. Nationally, the number of potato acres planted has declined since the early 1990s (USDA 
ESMIS, various issues), and this is true to a lesser extent for Idaho (Fig. 1A). However, yields have increased substantially during that same period (Fig. 1B), and as a result, potato production has remained relatively flat (Fig. 1C).

Certification. Many states have seed potato certification programs. All programs perform visual inspections for mosaic, and an increasing number perform laboratory assays for PVY along with other economically important potato viruses. (An overview of U.S. seed potato certification programs and practices is in Frost et al. [2013].) Table 1 compares field tolerances for Montana and several other major seed potato-producing states. Leaf testing thresholds differ from field tolerances and apply only to seed sold for recertification; the threshold for Montana seed is $0.5 \%$ for generations $\geq 2$; earlier generations cannot be sold.

The Montana State University Seed Potato Certification Program is grower supported and provides seed testing and inspection as well as information and research for seed potato growers in Montana. Based on tests and field inspections, they provide certification for seed potato producers on a year-to-year basis. All fields are visually inspected a
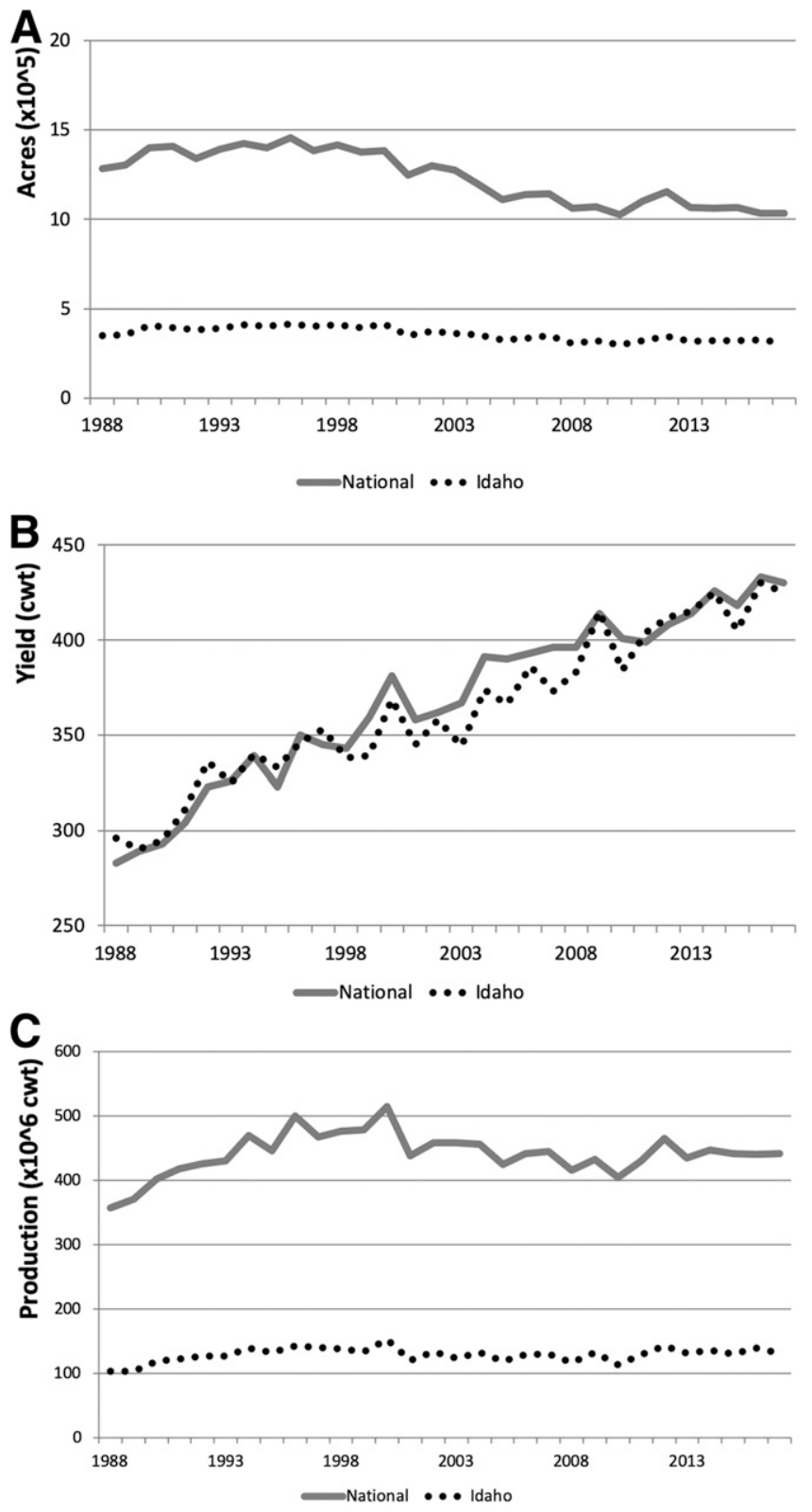

Fig. 1. A, Potato acreage planted in Idaho and the United States from 1988 to 2017. B, Average potato yields per acre (hundredweight [cwt]) in Idaho and the United States from 1988 to 2017. C, Total potato production (cwt) in Idaho and the United States from 1988 to 2017. minimum of two times, and leaf testing is performed for PVY and potato viruses $\mathrm{X}$ and A for the summer crop. An additional "postharvest" test follows in which samples from the summer's crop in Montana are grown in Hawaii in the winter and then tested. Montana has been testing for potato viruses for $>40$ years and currently performs $>600,000$ tests each year in both summer and as postharvest testing. Each generation of seed has a set tolerance for PVY and other diseases that it must meet to be sold as certified seed. Selling noncertified seed is illegal in Montana. This means that, if seed does not meet certification standards, it must be sold as seed for commercial production in another state, sold in a nonseed (much lower-valued) market, or disposed of. Seed potatoes produced in Montana are sold to seed potato producers in Montana and other states to be grown as certified seed (recertification) as well as to commercial growers throughout the United States; therefore, this program has wide-ranging impacts.

Previous economic studies. The impact of seedborne PVY on commercial potato production is a combination of yield and quality impacts. PVY has been shown to reduce yields by as much as $79 \%$ (Hane and Hamm 1999). Aryal et al. (2019) examined the qualitative impacts of PVY. They found that, in the two most common varieties grown in Idaho (Russet Burbank and Russet Norkotah), PVY infections not only reduced yield but also, reduced the amount of U.S. No. 1 potatoes (the most valuable potato grade) produced (91\% of all Idaho potatoes produced are Russet potatoes [USDA ESMIS 2017]). PVY also tended to increase the amount of "dry eliminators" or process-grade potatoes-lower-valued potatoes only usable in dehydration or otherwise processed.

Although several studies have examined the impact of PVY on commercial potato production (Nolte et al. 2004; Whitworth et al. 2006), no studies have evaluated the economic benefits from screening for PVY in seed potatoes. Horton et al. (1988) provided an examination of the benefits of a newly established seed potato screening program in South Korea. The authors noted a near doubling of Korean potato yields after the establishment of the certification program and conservatively attributed half of the yield gain to improved seed through the certification program. They found a $\$ 28$ million annual benefit or $\$ 41$ million in 2018 dollars. This translates to an annual benefit per acre of $\$ 364$ or $\$ 534$ in 2018 dollars and a 24:1 benefit to cost ratio of establishing the program. (We inflate economic values estimated in the past to 2018 dollars using the GDP index published by the Federal Reserve [https://fred.stlouisfed.org/series/GDPDEF].)

Fuglie et al. (1999) estimated the value of introducing virus-free sweet potato planting material in Shandong province in China. They found that yields increased by $30 \%$ for adopters of original (the first generation available to farmers) screened seed, and they found a $22 \%$ production increase for Shandong province overall. They estimated an annual benefit of $\$ 145$ million ( $\$ 212$ million in 2018 dollars) per year in the Shandong province alone, and they estimated $\$ 1.6$ billion per year for all of China from the introduction of the program.

Table 1. Visual potato virus $Y$ field tolerance rates by generation and state ${ }^{\mathrm{a}}$

\begin{tabular}{lccccccc}
\hline & \multicolumn{7}{c}{ Percentage } \\
\cline { 2 - 8 } & Nuclear & G1 & G2 & G3 & G4 & G5 & G6 \\
\hline Montana & 0.00 & 0.00 & 0.10 & 0.20 & 0.50 & $\mathrm{n} / \mathrm{a}$ & $\mathrm{n} / \mathrm{a}$ \\
Idaho & 0.00 & 0.00 & 0.25 & 0.50 & 0.75 & 1.00 & 1.00 \\
Oregon & 0.00 & 0.10 & 0.30 & 2.00 & 2.00 & 3.00 & $\mathrm{n} / \mathrm{a}$ \\
Washington & 0.00 & 0.10 & 0.20 & 0.50 & 1.00 & 2.00 & $\mathrm{n} / \mathrm{a}$ \\
Colorado & 0.00 & 0.00 & 0.20 & 3.00 & 3.00 & 3.00 & 3.00 \\
\hline
\end{tabular}

a Disease tolerance rates are for tolerance in the field; some states have standards specific to potato virus $Y$ for postharvest testing, with additional field visits if the first is a failed visit. This table reflects the standards in place over the years for which we have data. Note that definitions of generation $(G)$ may vary from state to state. Montana allows G5 seed (but they did not during the period for which we have data). The sources for this information are as follows: Montana: Montana State University Seed Potato Certification Program (2014); Idaho: Idaho Crop Improvement Association (2016) and Idaho Office of the Administrative Rules Coordinator (2012); Oregon: Oregon Seed Certification Service (2016); Washington: Washington State Department of Agriculture (2015); and Colorado: Colorado State University (2015). 
For Shandong province, average annual benefits per acre were $\$ 172$ in 2018 dollars.

Guenthner et al. (1991) estimated the average annual value of implementing a mandatory seed law in the state of Maine as $\$ 149$ per acre. The benefit, calculated as a change in grower profit, resulted from estimated increased yield and production and reduced seed rejection rates. They did not estimate benefits and costs of establishing a seed screening and certification program-only the change in grower profits from making certified seed use mandatory.

Many other studies have examined the economic effects of other plant viruses and/or virus control-for example, the exclusion of banana bunchy top virus in Australia (Cook et al. 2012); optimal control of vector-virus-plant interactions in a potato leafroll virus context (Marsh et al. 2000); the combined effects of climate, aphid infestation, and viruses on pulse crop production (Elbakidze et al. 2011); and the economic effects of viruses and virus screening programs for grapes (Atallah et al. 2015).

\section{Materials and Methods}

Potato yields, prices, PVY, other pest pressures, and other factors vary by both variety and region among other factors. Additionally, the severity of the effects from PVY differs over each of the five main virus strains (Schramm et al. 2011), and it is possible to find more than one strain in a given potato crop. As a result, we examine the effects of an "average strain" or to be more precise, an average across strains in the samples in our dataset.

The losses incurred by seed potato growers as a result of PVY and the benefit from using PVY-screened plants were estimated based on measures of "variable profits," which was defined for the purposes of this paper as gross revenue minus virus-related costs for a representative acre of commercial potato production. Virus-related costs include the costs of labor and materials required for rogueing plants with virus symptoms, any price premium for PVY-screened plants, and loss of production from reduced yield from diseased plants. The remaining "profit" must cover overhead costs, including equipment depreciation, maintenance, and property taxes as well as cultural costs not related to PVY, such as fertilizer application and irrigation

Model. The below equation describes variable profit for a representative acre in this region in a given year. For the sake of simplicity, our variable profit function only considers costs and losses relating to PVY, allowing us to focus on the role of the disease in growers' decision-making process. Variable profit here is revenue minus losses from PVY less costs relating to PVY in terms of various forms of prevention. (Other input costs could be included, but in the maximization problem that we describe, they would be differentiated away after we take the partial derivative with respect to disease at planting.) Price $(p)$ and yield $(y)$ as well as PVY-related losses at harvest $\left(d^{H}\right)$ vary over potato variety $(i)$ and generation $(j)$ :

$$
\pi=\sum_{i, j}\left(p_{i j} y_{i j}\left(1-d_{i j}^{H}\left(d_{i j}^{P}\right)\right)-c\left(d_{i j}^{P}\right)\right)
$$

More precisely, variable profit, $\pi$, is a function of $p$, the price per hundredweight of potatoes; $y$, the yield in hundredweight per bearing acre of plants without PVY; $d^{H}$, the percentage of loss from PVY at the end of the season, which is a function of the amount of virus planted $d^{P}$; and $c$, the costs associated with screening, certification, and PVY prevention. PVY-related costs consist of monitoring for PVY (walking rows to scout for disease), rogueing symptomatic vines, seed costs, and insecticide and crop oil applications or other prevention or control methods. (We do not impose a functional form on the cost function in our theoretical model, which allows flexibility. Costs likely are relatively flat in per acre terms in most cases. Rogueing costs do increase with disease, meaning that, in the case of high disease incidence, labor costs will increase substantially-but these cases are fairly rare. Because monitoring in the form of walking through fields must occur either way, the additional cost to pull vines here and there is relatively low unless disease is severe.)
Optimally, growers would choose a level of disease at planting such that the value of the marginal effect of resulting loss at harvest is offset by the marginal difference in costs from a marginal change in disease at planting $d^{P}$ :

$$
-p_{i j} y_{i j} \frac{\partial d_{i j}^{H}}{\partial d_{i j}^{P}}=\frac{\partial c_{i j}}{\partial d_{i j}^{P}}
$$

Because there is some tolerance for disease (Montana State University Seed Potato Certification Program 2014), $d^{P}$ is often not equal to zero. In this way, the potato program is inherently different from screening efforts that aim to provide $100 \%$ disease-free plants, such as is the case in many perennial crop screening programs (Table 1 shows the field tolerance levels for certification of seed tubers by generation; note that commercial potatoes are typically grown from generation 3 seed). Another difference from perennial plant screening programs is the span of time over which the disease spreads. In perennial plants, virus can spread in the field over multiple years. In annual crops, virus spreads in the field within a season, and efforts can be made to limit or remove spread from year to year. Because seed in Montana must be inspected and screened each year, the certification program limits intraseason spread to tolerance levels.

Net income per representative acre is calculated using parameters derived from a range of sources. In the years 2012 to 2016, potato growers in the United States received an average of $\$ 9.31$ per hundredweight, and the average yield was 420 hundredweight per acre; average revenue was $\$ 3,910$ per acre. In Idaho, average potato revenue was calculated to be $\$ 3,044$ per acre during that time period (USDA National Agricultural Statistics Service [NASS] 2018). Table 2 illustrates the average production, yield, and price for potatoes for the 2012 to 2016 period.

Montana seed potato laboratory data. Using PVY test data from the Montana Seed Potato Certification Program, we can estimate PVY spread over the course of a season. We draw on 3,811 complete observations from 2005 to 2015 that include information on summer and winter test results for PVY along with several other diseases, grower location, variety, and generation. Each observation represents one seed lot submitted for testing. Notably, these data are from seed growers actively suppressing disease by rogueing and in some cases, spraying pesticide during the summer growing season.

Table 3 presents summary statistics from the test data. Year represents the year in which each sample was submitted ranging from 2005 to 2015. SummerPVY_N and WinterPVY_N are the numbers of samples tested in the summer and winter tests, respectively. The number of samples required for submission depends on the generation, the number of acres, and whether the test is a summer (in-season) or winter (postharvest) test. In the summer, leaves are collected for tests. Each sample is a pooled group of 10 leaves. The percentage of plants with PVY in the population is estimated using the formula

$$
1-\sqrt[10]{1-X}
$$

where $X$ represents the proportion of positive tests to the total number of tests and 10 corresponds to the number of leaves pooled in each test (Montana State University Seed Potato Certification Program 2014). (In the summer test, all nuclear and generation 1 plants are tested. Generation 2 plants are tested at 200 plants per acre, generation 3 plants are tested at 100 plants per acre, and generation 4 plants are tested at 50 plants per acre. Although generation 5 seed potatoes can now be grown in Montana, we do not observe any in our dataset.)

The sampling formula yields more precise estimates when lot sizes are larger. There is also more possible variation in the estimates of incidences when disease incidence is lower; this is dictated by the sampling formula. Conversations with researchers involved in seed potato testing suggest that the goal of the formula is to keep disease below a (low) threshold; less concern is given to estimating very high disease incidence with precision because those lots would certainly be rejected (S. Siemsen, personal communication). 
Tubers from each seed lot from generations 1 to 4 are collected at harvest for the winter test. The minimum sample size for fields of between 1 and 40 acres is 400 tubers. An additional 400 tubers are collected for each additional 40 acres, with a maximum of 1,200 tubers per seed lot. Tubers are treated with Rindite or bromoethane to break dormancy (Bryan 1989) before shipping to Hawaii, where they are planted and grown. Tests are once again conducted in pooled groups of 10 leaves each. The number of samples tested in the winter test varies substantially because although the number of tubers submitted is standardized, not all tubers grow into plants (Montana State University Seed Potato Certification Program 2014). (Tests are conducted on pooled groups of 10 leaves from 10 different plants. Ideally, a 400-tuber sample would produce 400 plants that would create 40 test samples. The rules for winter testing have changed since 2015 when the data in this study conclude; the protocol reported here reflects the rules in place during the years in our dataset.)

The variable SummerUnderTol measures the percentage of generations 2 to 4 samples submitted that came in under the Montana tolerance for PVY (for generations 2 to 4 , that tolerance is $0.5 \%$; nuclear and generation 1 cannot be sold outside Montana). The winter test is not binding for certification purposes but can warn growers of a potential outbreak the following season. Overall, the average proportion of generations 2 to 4 summer samples that met the tolerance in our dataset is 0.96 or $96 \%$ of all samples submitted.

Generation, the seed generation of the sample submitted for testing, determines the disease tolerance for certification. In this dataset, it ranges from zero (nuclear) to four, the last allowed seed generation. The median generation submitted for testing is generation 2. Montana has begun to allow generation 5 seed, but in our dataset, generation 4 was the last generation.

SummerPVY_per and WinterPVY_per represent the calculated percentages of PVY in the field extrapolated from the sample percentages. In both cases but especially for winter, the mean is much greater than the median value for the lots submitted. For the winter test, the mean is 0.64 , whereas the median is 0 , reflecting that

Table 2. Average potato production in Idaho and the United States from 2012 to $2016^{\mathrm{a}}$

\begin{tabular}{lccccc}
\hline & $\begin{array}{c}\text { Acres planted, } \\
\mathbf{1 , 0 0 0} \text { acres }\end{array}$ & $\begin{array}{c}\text { Production, } \\
\text { million cwt }\end{array}$ & $\begin{array}{c}\text { Yield, } \\
\text { cwt/ } \\
\text { acre }\end{array}$ & $\begin{array}{c}\text { Price, } \\
\text { \$/cwt }\end{array}$ & $\begin{array}{c}\text { Planting } \\
\text { MT seed, \% }\end{array}$ \\
\hline Idaho & 326 & 136 & 417 & 7.30 & 33 \\
National & 1,076 & 445 & 420 & 9.31 & - \\
\hline
\end{tabular}

a Acres planted, production, yield, and price are from USDA National Agricultural Statistics Service (NASS) (2018). Prices are inflated to 2016 dollars using the GDP deflator available at https://fred.stlouisfed.org/series/ GDPDEF. Column 6 is estimated from seed lot data provided by A. Westra (personal communication) for Idaho. cwt, hundredweight; MT, Montana.

Table 3. Summary statistics ${ }^{\mathrm{a}}$

\begin{tabular}{lrrrrc}
\hline & Mean & \multicolumn{1}{c}{ SD } & Median & Minimum & Maximum \\
\hline Year & 2010.01 & 2.97 & 2011 & 2005 & 2015 \\
SummerPVY_N & 709.93 & 969.74 & 371 & 1 & 8696 \\
WinterPVY_N & 29.37 & 20.59 & 28 & 1 & 197 \\
SummerUnderTol & 0.96 & 0.19 & 1 & 0 & 1 \\
Generation & 1.84 & 0.84 & 2 & 0 & 4 \\
SummerPVY_per & 0.07 & 0.34 & 0 & 0 & 12.83 \\
WinterPVY_per & 0.56 & 3.37 & 0 & 0 & 100 \\
\hline
\end{tabular}

a $N=3,811$; this is our estimation sample and applies for all rows except SummerUnderTol. SummerUnderTol is the proportion of generations 2 to 4 samples (those that can be sold) with potato virus Y (PVY) less than tolerance to be planted back as Montana seed. $N=2,474$ for this subsample. Four winter PVY observations that are listed as outliers in both dfbeta and Cook's D outlier diagnostics are winsorized; for these observations, the DF Beta statistic is greater than twice the square root of the number of observations, and Cook's $D$ is $>1$. there are many data points near 0 but a few outliers closer to or at $100 \%$ that heavily influence the calculated mean. We used Cook's Distance and DF Beta outlier diagnostics (using Stata's cooksd and dfbeta postestimation options) after regressing WinterPVY_per on SummerPVY_per to identify outliers in the WinterPVY_per data. Four observations with winter PVY percentages estimated to be $100 \%$ both had a DF Beta statistic greater than twice the square root of the number of observations (suggested by Belsley et al. [2004] as an outlier diagnostic) and had a Cook's $D$ statistic greater than one (suggested by Cook and Weisberg [1982] as an outlier diagnostic). We winsorized these four observations to the next highest value.

Figure 2 shows winter test results plotted over summer test results. Each test result-summer and winter-shows the percentage of PVY in a particular lot of potatoes tested. The size of each hollow circle data point in Figure 2 represents its relative weight in number of observations at that particular point. The results are densely clustered near zero. Seven 100\% winter PVY estimates are evident. Figure 2A shows observations prewinsorization; Figure 2B shows observations after the four outliers are winsorized.

To better understand the relationship between PVY levels in the summer and winter tests, we estimate a series of regression models that control for a number of factors for which we have data. For both the Variety and FarmID indicator variables, we define a "rest of" category for those varieties and farm identifications with $<50$ observations in the dataset. Note that we lack information on adjacency of other potato fields from which disease could spread. Seed potato growers strive to isolate their fields from sources of disease, but in some cases, they may not be able to do so (adjacent fields with high
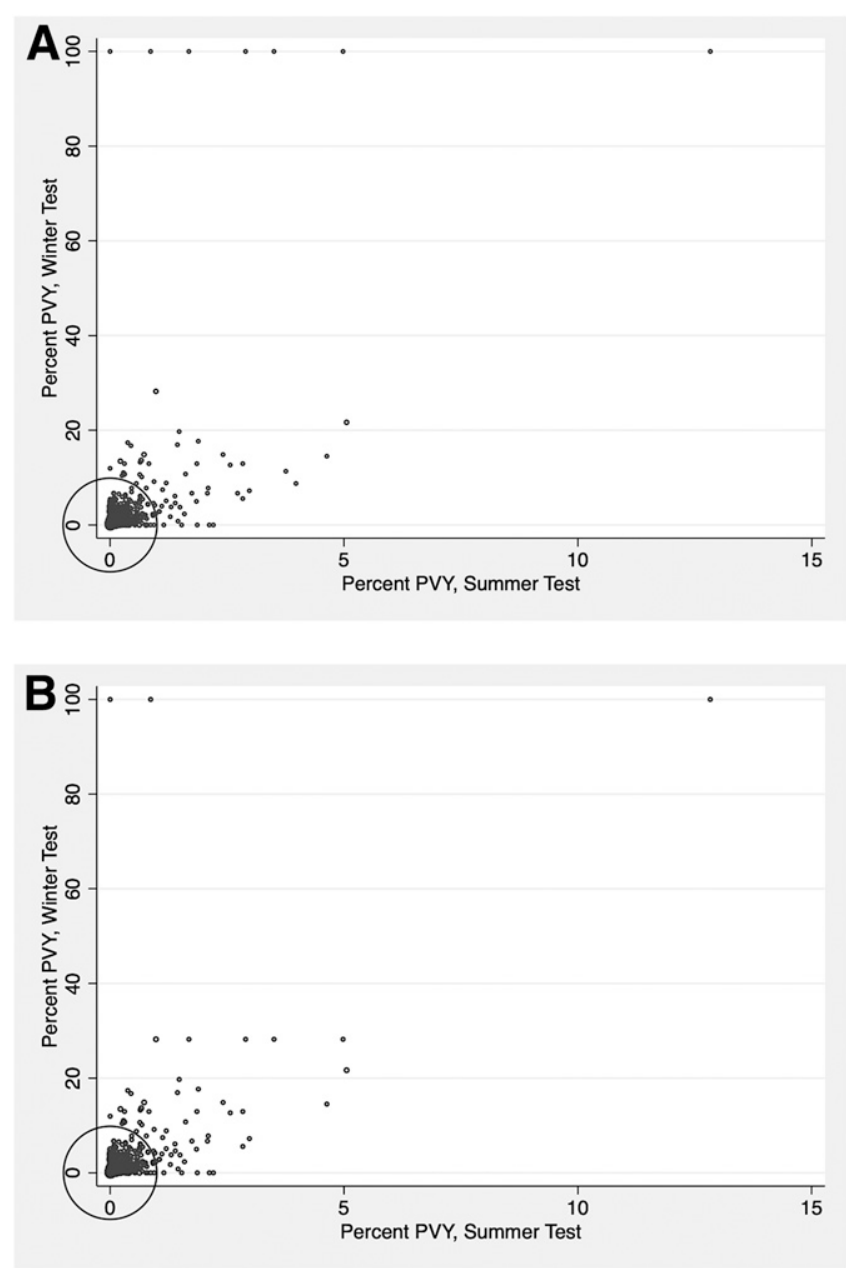

Fig. 2. A, Summer and winter potato virus $Y$ (PVY) test results weighted by the number of observations prewinsorization. B, Summer and winter PVY test results weighted by the number of observations postwinsorization. 
disease incidence are one potential explanation for those outliers that test at $0 \%$ PVY in the summer test and very high or $100 \%$ PVY in the winter). However, we are unable to directly control for this potential influence in our dataset.

We estimated the following general equation:

$$
\begin{aligned}
\text { WinterPVY_per }_{i}=\beta_{0} & +\beta_{1} \text { SummerPVY_per }_{i}+\sum_{j} \beta_{2, j} \delta_{i, j} \text { Variety }_{i} \\
& +\sum_{k} \beta_{3, k} \delta_{i, k} \text { Year }_{i, k}+\sum_{i} \beta_{4, l} \delta_{i, l} \text { County }_{i, l} \\
& +\sum_{m} \beta_{5, m} \delta_{i, m} \text { Generation }_{i, m} \\
& +\sum_{n} \beta_{6, n} \delta_{i, n} \text { FarmID }_{i, n}+\varepsilon_{i}
\end{aligned}
$$

\section{Results}

Disease spread results. Table 4 shows ordinary least squares (OLS) regression results using these data and dummy controls for potato variety (because some varieties are perceived to be more PVY susceptible than others), year (some years are "outbreak" years), county (some counties may have higher disease pressure than others), generation grown (because different generations have different disease tolerances), and an identifier for the farm. The percentage of PVY incidence in the winter test is the dependent variable in all regressions. We weight each regression by the number of samples submitted for the test in each observation. The coefficient on SummerPVY_per can be interpreted as the multiplication factor of spread over a season based on the amount of PVY in the seed planted.

Several observations with very high PVY incidence in the winter test play a large role in regression results. Comparing column (2) in Table 4, in which the data are untransformed, with column (4) in Table 4, in which the four winter PVY observations that are listed in both dfbeta and Cook's D outlier diagnostics are winsorized yields a spread coefficient that is approximately $20 \%$ smaller. The regressions are otherwise identical, highlighting the influence of outliers on OLS regression results.

Table 4. Disease spread ordinary least squares regression results ${ }^{\mathrm{a}}$

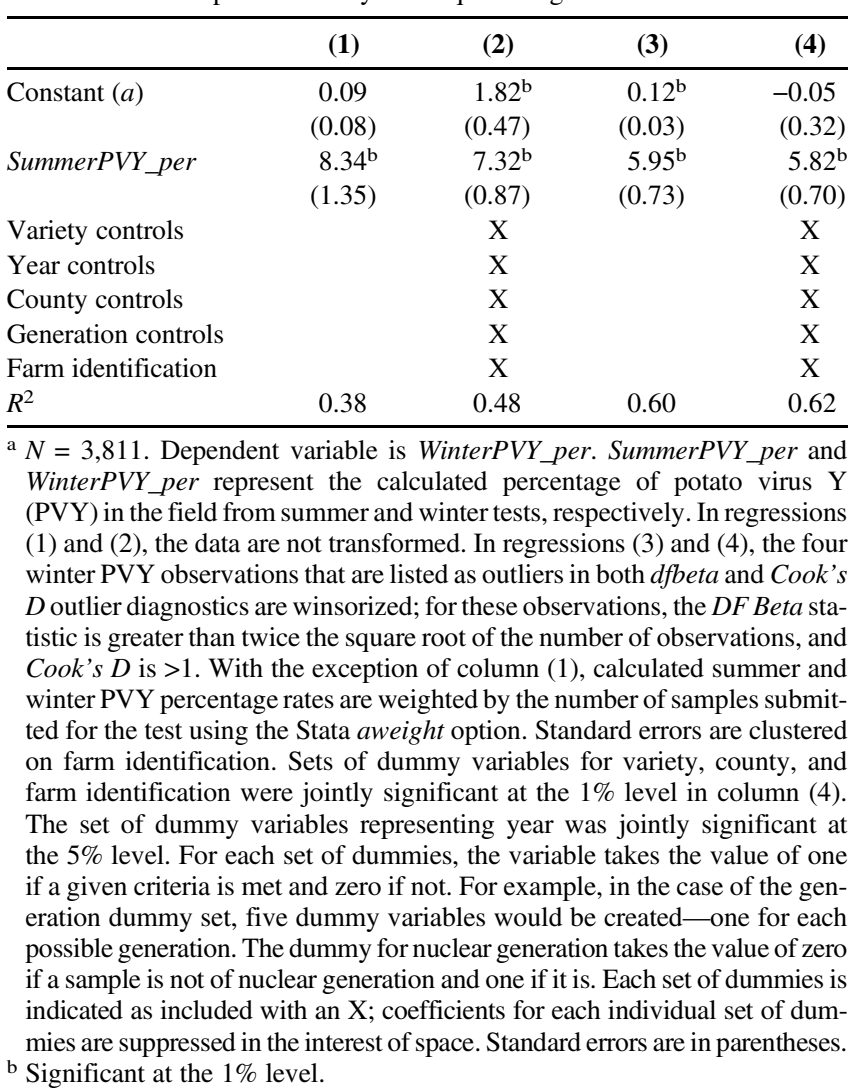

Regardless of how we address the issue of outlier winter PVY tests, the coefficient on summer incidence is positive and significant in all regressions, ranging from 5.82 to 8.34 in the OLS regressions. $F$ statistics suggest that each of the sets of dummy variables is jointly significant at the $95 \%$ level or greater, with the exception of generation. We estimate standard errors clustered on farm identification; one farm may have an environment more prone to disease as well as different disease management practices than another. We use guidance from Cameron and Miller (2015) in determining the number of restrictions that we are able to test to establish joint significance. (In this case, we can test a number of restrictions less than or equal to the number of clusters minus one.)

We report results from quantile regressions in Table 5. Quantile regressions regress to the quantile specified rather than regressing to the mean; regressing to the median rather than the mean limits the influence of outliers. Because of this, a quantile regression at the median is our preferred model. Because of the large number of dummy variables, we were unable to consistently estimate the quantile regressions with standard errors clustered on farm identification. Instead, we bootstrap our standard error estimates.

Table 5 shows regression results for winter PVY incidences at the 0.25 , median, and 0.75 quantiles with all control variables. We again weight each regression by the number of samples submitted for the test in each observation. Lower winter PVY incidence (lower quantiles) is associated with lower rates of spread both with and without dummy controls. The spread coefficient for our preferred model (median quantile) is 4.22 , and it is significant at the $1 \%$ level. Coefficients on the summer PVY incidence variable range from 1.86 (0.25 quantile) to 7.74 ( 0.75 quantile). Notably, the pseudo- $R^{2}$ values of the regressions improve as the quantile increases; models explain more of the variation in winter PVY as winter PVY increases. Given that the magnitude of the coefficient on summer PVY increases with each increasing quantile, this finding is not overly surprising. Joint significance tests suggest that farm identification and year are jointly significant at the $5 \%$ or greater level. The significance of the farm identification variables in all of our regressions provides support for what both buyers and growers believe; farm management practices and other differences between growers matter in providing quality control in seed potato production and determining whether seed

Table 5. Disease spread linear quantile regression results ${ }^{\mathrm{a}}$

\begin{tabular}{lccc}
\hline & $(\mathbf{1})$ & $\mathbf{( 2 )}$ & $\mathbf{( 3 )}$ \\
\hline Quantile & 0.25 & 0.5 & 0.75 \\
Constant $(a)$ & 0.00 & 0.00 & 0.03 \\
& $(0.02)$ & $(0.05)$ & $(0.31)$ \\
SummerPVY_per & $1.86^{\mathrm{b}}$ & $4.22^{\mathrm{b}}$ & $7.74^{\mathrm{b}}$ \\
& $(0.42)$ & $(0.45)$ & $(0.68)$ \\
Variety controls & $\mathrm{X}$ & $\mathrm{X}$ & $\mathrm{X}$ \\
Year controls & $\mathrm{X}$ & $\mathrm{X}$ & $\mathrm{X}$ \\
County controls & $\mathrm{X}$ & $\mathrm{X}$ & $\mathrm{X}$ \\
Generation controls & $\mathrm{X}$ & $\mathrm{X}$ & $\mathrm{X}$ \\
Farm identification & $\mathrm{X}$ & $\mathrm{X}$ & $\mathrm{X}$ \\
Pseudo- $R^{2}$ & 0.04 & 0.20 & 0.38 \\
\hline
\end{tabular}

a $N=3,811$. Dependent variable is WinterPVY_per. SummerPVY_per and WinterPVY_per represent the calculated percentage of potato virus $\mathrm{Y}$ (PVY) in the field from summer and winter tests, respectively. Four winter PVY observations that are listed as outliers in both dfbeta and Cook's D outlier diagnostics are winsorized; for these observations, the DF Beta statistic is greater than twice the square root of the number of observations, and Cook's $D$ is $>1$. We report standard errors bootstrapped with 500 replications in parentheses. Dummy variables for farm identification are jointly significant at the $1 \%$ level. Dummy variables for year are jointly significant at the $5 \%$ level across quantiles. For each set of dummies, the variable takes the value of one if a given criteria is met and zero if not. For example, in the case of the generation dummy set, five dummy variables would be created —one for each possible generation. The dummy for nuclear generation takes the value of zero if a sample is not of nuclear generation and one if it is. Each set of dummies is indicated as included with an X; coefficients for each individual set of dummies are suppressed in the interest of space. Standard errors are in parentheses. b Significant at the $1 \%$ level. 
will meet the disease tolerances of certification standards. (We also explored a logistic quantile regression [Orsini and Bottai 2011 has details]. The coefficient estimates for the SummerPVY_per variable were very close to those of the linear quantile [ 4.00 versus 4.22 as the coefficient on the SummerPVY_per variable at the median; 2.16 versus 1.86 and 5.12 rather than 7.74 for the 0.25 and 0.75 quantiles, respectively]. However, the model fit was poor relative to that of the linear quantile models.)

The value of foregone production and benefits from the Montana certification program. In what follows, we document estimates of losses from PVY and benefits from the Montana Certified Seed Potato Program to potato growers in Idaho, one of Montana's biggest seed customers. We draw from our regression results, other studies, and several assumptions.

The average disease incidence across all seed in our sample is $0.065 \%$ in the summer test. In comparison, seed that passes Montana inspection has an average PVY incidence of $0.025 \%$ or roughly one-third of the average for all seed submitted for testing. Simply comparing projected losses for a year of growing potatoes with these percentages alone would understate the benefits of the program; that comparison would leave out the benefits accruing as one generation of clean seed progresses to later generations of seed and commercial production.

Using the median quantile regression results from the laboratory data presented in Table 5, we can provide an estimate of benefits and costs over time, assuming that spread over multiple years is similar to what we capture in the dataset measuring disease in summer and winter tests. We compute disease incidence in each year for two scenarios. In the first scenario, referred to hereafter as "certified," a commercial grower purchases screened and certified seed each year. In the other scenario, "uncertified," seed is saved, and PVY spreads from year to year using estimates from our regression results. Each scenario plays out over a 5-year time horizon, the number of generations allowed by the Montana certification program. (To explore sensitivity of our results to alternative time horizons, we include a sensitivity analysis of our results using varying time horizons in Supplementary Table S1.)

Our calculations assume that, over the 5-year horizon that we examine (other than practices already used by growers submitting samples for disease testing), there are no additional constraints on PVY spread in the absence of the seed certification program. Although additional strategies to constrain PVY might be used in the event of the certification program being halted, we do not model those here. Ours is a comparison between 5 years of the Montana certification program as it currently stands and 5 years of growers' disease management actions being essentially the same without any certification program.

In the uncertified scenarios, PVY spreads to approximately $85 \%$ incidence in the last year of our 5-year time horizon using our preferred model (a factor of disease spread of 4.22 per year). Even using the most conservative estimates of disease spread (a factor of 1.86 each season) starting with the average incidence in unscreened Montana seed $(0.065 \%)$ without the screening and removal of PVY-infected seed, incidence would be at $100 \%$ in year 12 . In our preferred model, after 6 years, the PVY incidence in the representative acre is $100 \%$. Using the larger estimates for the spread multiplier, PVY would reach $100 \%$ much more quickly. The 7.74 -fold spread from column (3) in Table 5 would imply reaching $100 \%$ in just 4 years. Because of the fact that seed growers actively manage disease as well as how estimates of percentage of infection are calculated, we have few data points near $100 \%$, and predictions near $100 \%$ disease should be viewed with caution. Still, these spread projections highlight the importance of considering potential spread over time if PVY was allowed to proliferate in the absence of the screening and provision of clean seed from the certification program. Figure 3 shows PVY incidence using a range of alternative estimates from the quantile regressions for rate of spread over a 15-year time horizon, which allows examination of the disease incidence trajectory to $100 \%$ using each quantile regression result.
We set beginning of season disease levels to the average PVY incidence in seed that meets tolerance for the Montana program for the certified scenario- $0.025 \%$. At the end of the season, using our preferred model, we predict PVY incidence to be $\widehat{\beta_{0}}+0.025 \times \widehat{\beta_{1}}$ or $0.025 \times 4.22$ because our estimated intercept is 0 . We estimate the economic loss per acre using work by Aryal et al. (2019), who combine estimated effects of PVY on both yield and grade to calculate losses in commercial potato production. They estimate that, for each $1 \%$ PVY incidence per acre, $\$ 11.93$ is lost if potatoes are sold as fresh and $\$ 9.17$ is lost if potatoes are sold for processing. Approximately $66 \%$ of potatoes in Idaho are used for processing, with the remaining $33 \%$ being sold as fresh and other (USDA National Agricultural Statistics Service [NASS] 2016, 2017). Although current details on potato use are not available at the state level, at the national level the vast majority of the "other" category is seed (National Potato Council 2017). We opt to use the fresh model to estimate losses for the fresh/other category. Although the fresh model will undervalue PVY losses for seed, the most valuable market for potato growers, it does allow them to be counted. To compute the economic value of estimated losses, we weight such that a representative acre includes $66 \%$ of potatoes produced for processing and $33 \%$ sold fresh. We then discount each year's losses to present value using a $3 \%$ discount rate.

Table 6 shows these calculations using our preferred regressionthe median quantile regression with all dummy controls included. The second column in Table 6 shows the average annual current cost of PVY to Idaho growers using Montana seed. Under current Montana certification standards, we estimate that PVY in seed causes very small losses - $\$ 1.00$ per acre planted with Montana seed or approximately $\$ 106,000$ per year for all of the Idaho acreage planted with Montana seed. (The 5-year average 2012 to 2016 acreage planted in Idaho is 326,200 [USDA National Agricultural Statistics Service (NASS) 2018]. We estimate that 33\% of Idaho seed comes from Montana using seed lot test data for years 2013 to 2017 [A. Westra, personal communication]. The net present value of losses from PVY and benefits from the program over the 5 years can be calculated by multiplying the average annual values by five.) These losses can be compared with those that we project would occur if the certification program stopped PVY screening - the uncertified scenario. We estimate the average annual cost of PVY per acre under the uncertified scenario to be $\$ 206$ per acre per year or $\$ 21.70$ million for the state of Idaho over the 5-year time horizon. The loss estimates are made up of small losses in early years and greater (although discounted) losses in later years as the disease spreads. Because the current loss estimates are so small relative to potential losses, the value of the program is close to the value of the loss if there was not a program in place. We estimate the total benefit of Montana's program to Idaho to average \$205 per acre or \$21.59 million per year over the 5-year time horizon.

However, changes in environmental factors, such as weather, vector pressure, variation in PVY strains, or climate change, as well as

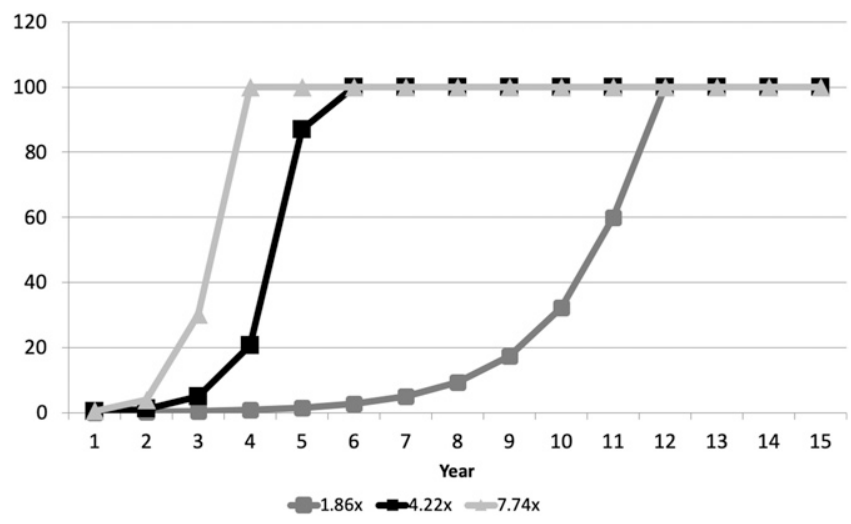

Fig. 3. End of season potato virus $Y$ incidence for alternative estimates of spread. 
evolving technologies to address disease may influence both the baseline incidence and the spread of PVY moving forward. Our estimates of both overall losses from PVY and the benefit of the Montana program to Idaho are particularly sensitive to changes in how PVY spreads. We present several loss and certification program benefit estimates in Table 6, drawing from the range of our quantile regression results. Using the 0.25 quantile, we estimate the total benefit of the Montana program to Idaho to average approximately $\$ 534,000$ per year; at the 0.75 quantile, we estimate that benefit to average $\$ 45$ million per year.

The average expense total from the 2014 to 2016 crop year Montana seed potato laboratory cash flow statements was $\$ 1.1$ million. Comparing this budget with the estimated benefits accrued by Idaho growers alone, we estimate a benefit to cost ratio of approximately 20:1.

\section{Discussion}

Our work supports existing research suggesting that PVY spreads in dramatic ways over the course of a growing season and that plant screening and certification programs are valuable. We introduce new data and analysis that connect PVY incidence and spread in seed potato production with models of disease spread and corresponding economic losses in the commercial potato industry.

We find that the amount of PVY in the seed in the summer test is a very strong predictor of PVY in the winter test. Both PVY at planting and the spread over the course of the growing season have major implications for the profitability of both seed and commercial potato growers. Seed growers observe losses in quantity and quality as well as potentially catastrophic losses if their seed lot does not meet tolerance and cannot be sold in the seed market. Commercial potato grower returns can be significantly reduced by PVY in seed stocks resulting from decreased yield and quality. Our estimates quantify the importance of the Montana screening program to Idaho while also suggesting the importance of the Montana screening program to other states. Our work supports existing evidence of the importance of screening programs nationally and internationally.

We estimate an average annual benefit of $\$ 205$ per acre or approximately $\$ 22$ million to the state of Idaho. Our per acre estimate can be compared with other studies evaluating the benefit from introducing certification programs in other crops. Our per acre estimate is substantially less than that in the work by Horton et al. (1988), who estimated a benefit of $\$ 534$ per acre from the introduction of the South Korean potato certification program (after inflation to 2018 dollars). However, our estimate of the benefit to cost ratio from the Montana program to Idaho $(20: 1)$ tracks closely with that study, which reported a 24:1 benefit to cost ratio.

Another example of a study finding perhaps surprisingly large estimated benefits from a disease screening program is that of Fuglie et al. (1999). They find that "the success of this one intervention is more than enough to pay for all of the resources devoted to sweet potato research and extension in the developing world" (Fuglie et al.

Table 6. Average annual potato virus $\mathrm{Y}$ costs and benefit from the Montana certification program to Idaho potato growers ${ }^{\mathrm{a}}$

\begin{tabular}{lccc}
\hline & $\begin{array}{c}\text { Current } \\
\text { cost }\end{array}$ & $\begin{array}{c}\text { Cost without } \\
\text { program }\end{array}$ & $\begin{array}{c}\text { Benefit of } \\
\text { program }\end{array}$ \\
\hline 0.25 Quantile; $\beta_{1}=1.86$ & & & \\
$\quad$ \$/Acre & 0.44 & 5.51 & 5.07 \\
$\quad$ \$Thousands/Idaho & 47 & 580 & 534 \\
0.50 Quantile; $\beta_{1}=4.22^{\mathrm{b}}$ & & & \\
$\quad$ \$/Acre & 1.00 & 205.98 & 204.98 \\
$\quad$ \$Thousands/Idaho & 106 & 21,697 & 21,591 \\
0.75 Quantile; $\beta_{1}=7.74$ & & & \\
$\quad$ \$/Acre & 1.84 & 429.75 & 427.91 \\
\$Thousands/Idaho & 194 & 45,268 & 45,074 \\
\hline
\end{tabular}

a Average annual values are calculated over a 5-year time horizon. The regression model is from Table $5 ; \beta_{1}$ represents the disease spread coefficient. Discount rate is $3 \%$. Columns may not add exactly because of rounding.

b Our preferred model is for the median quantile, $\beta_{1}=4.22$.
1999). Their estimate of an annual program benefit of $\$ 172$ per acre (in 2018 dollars) is very close to our estimate of $\$ 205$ per acre.

Seed certification programs, such as the Montana State University Seed Potato Certification Program, screen seed for PVY and other viruses and certify that disease falls below certain preestablished tolerances. Our analysis supports other studies (Atallah et al. 2015; Fuglie et al. 1999; Horton et al. 1988) in providing evidence that screening is economically important.

Limitations. Although the dataset that we use is the best available to us, it is imperfect in several senses. The first limitation is that we do not observe beginning and end of season disease incidence. Instead, we model spread as the difference in disease in the summer and winter tests. Although the difference between the two tests provides an estimate of disease spread from one season to the next, we cannot calculate that estimate with precision. Each summer test is not taken at the same point in the growing season or a plant's growth cycle. Additionally, we are unable to observe in-field PVY spread that occurs in the time between plant emergence and when the summer test leaf samples are taken.

A second and related limitation is that we observe estimated, but not actual disease incidence. The PVY incidence reported in our dataset is calculated from a pooled leaf test and standard sampling formula (we include details of the formula in the section on Montana seed potato laboratory data). Although this formula and variations of it are used by several states' certification programs, several important caveats must be noted. The formula yields more precise estimates when lot sizes are larger and greater precision in the estimates of incidences when disease incidence is lower. These properties of the formula serve a purpose to those providing certification: less concern is given to estimating very high disease incidence with precision because those lots would certainly be rejected (S. Siemsen, personal communication). However, it also means that we observe higher values with less confidence. The quantile regressions estimated at higher quantiles should be interpreted with greater caution.

We also lack information on PVY strain. Depending on the strain and strain-cultivar interaction, both the spread and the effect of PVY can have widely varying implications. The disease test dataset that we draw from does not differentiate between different strains. The economic model that we use to estimate the value of losses, and the testing program averages over a range of alternative unknown strains.

Understanding of the importance of strains in PVY epidemiology progressed markedly in the years during which the dataset that we use was being collected (2005 to 2015). For example, Mello et al. (2011) found no clear difference in aphids' ability to transmit five different PVY strains. However, newer work suggests that strain prevalence has shifted since then, and differences in transmission efficiency as well as cultivar resistance may be playing a role in the changing distribution of PVY strains in the population. Funke et al. (2017) found an increase in PVY ${ }^{\mathrm{N}-\mathrm{Wi}}$ (a recombinant strain of PVY $\left.{ }^{\mathrm{NTN}}\right)$, which is associated with potato tuber necrotic disease from 2011 to 2015-the later years in our study. MacKenzie et al. (2018a, b) found that PVY ${ }^{\mathrm{NTN}}$ spreads most efficiently. All of this suggests a shift in strain dominance, PVY spread, and effects on potato yield and quality over the period in which we observe PVY tests. Some of the effect of these shifts in strain dominance over time and from year to year should be picked up by our inclusion of year dummy variables. However, the Year variables also pick up variation in precipitation, other weather-related phenomena, and likely other unknowns, and therefore, we are unable to identify the role of strain with precision. Our models likely suffer from omitted variable bias because we lack a mechanism with which to observe or control for PVY strain.

These limitations should be carefully considered when assessing the overall message of our analysis. To address outliers and unknowns, we use outlier diagnostics and winsorization, utilize a quantile regression model, and also, conduct sensitivity analysis on our results, but we cannot address all of the concerns listed above. Overall, we find both a large benefit and benefit to cost ratio from Montana's seed potato screening and certification program. However, the precision of our estimates is limited by available data. Additionally, 
our models and the results that we produce using them are at least in part a function of our assumptions.

\section{Conclusion}

PVY continues to present economic problems for U.S. seed and commercial potato industries, and this work adds to documentation of the effects on yield, prices, and profit. Few management strategies are effective in reducing spread of the disease after it enters a field. New PVY strains that spread with greater efficiency coupled with the release of several varieties of potatoes that carry PVY infection but do not exhibit visible symptoms present new and greater challenges for managing PVY. The "latent varieties," in particular, cause challenges for on-farm disease management practices, such as rogueing. It may also be that PVY management is competing for salience in a crowded field of farm management decisions. Our work suggests that unobserved differences between individual farms - such as farm management practicesplay a role in disease presence and spread. The most important, however, is purchasing seed with lower disease presence.

\section{Acknowledgments}

We wish to acknowledge helpful feedback from Ken Frost, Susie Siemsen, Matteo Bottai, Cindy Binzen, and participants in the NC-1024 multistate group. Excellent research assistance was provided by Jay Matonte, Erika Refsland, and Molly DelCurto.

\section{Literature Cited}

Aryal, G. R., Rosenman, J., McIntosh, C. S., and Nolte, P. 2019. The effect of seedborne PVY on the yield and size of Russet Burbank and Russet Norkotah potatoes. Working paper, University of Idaho, Moscow, ID.

Atallah, S. S., Gómez, M. I., Conrad, J. M., and Nyrop, J. P. 2015. A plant-level, spatial, bioeconomic model of plant disease diffusion and control: Grapevine leafroll disease. Am. J. Agric. Econ. 97:199-218.

Belsley, D. A., Kuh, E., and Welsch, R. E. 2004. Regression Diagnostics: Identifying Influential Data and Sources of Collinearity. Wiley Interscience, Hoboken, NJ.

Bryan, J. E. 1989. Breaking dormancy of potato tubers. International Potato Center (CIP) Research Guide 16. http://cipotato.org/wp-content/uploads/publication\% 20files/research\%20guides/ResGuide32465.pdf

Cameron, C. A., and Miller, D. L. 2015. A practitioner's guide to cluster-robust standard inference. J. Hum. Resour. 50:317-372.

Colorado State University. 2015. Colorado rules and regulations for certification of seed potatoes. https://web.archive.org/web/20160421185105/http://www.colorado certifiedpotatogrowers.com/downloads/Rules-and-Regs.pdf

Cook, D. C., Liu, S., Edwards, J., Villalta, O. N., Aurambout, J.-P., Kriticos, D. J., Drenth, A., and De Barro, P. J. 2012. Predicting the benefits of banana bunchy top virus exclusion from commercial plantations in Australia. PLoS One 7:e42391.

Cook, R. D., and Weisberg, S. 1982. Residuals and Influence in Regression. Chapman and Hall, Boca Raton, FL.

Coutts, B. A., and Jones, R. A. C. 2015. Potato virus Y: Contact transmission, stability, inactivation, and infection sources. Plant Dis. 99:387-394.

Elbakidze, L., Lu, L., and Eigenbrode, S. 2011. Evaluating vector-virus-yield interactions for peas and lentils under climatic variability: A limited dependent variable analysis. J. Agric. Resour. Econ. 36:504-520.

Frost, K. E., Groves, R. L., and Charkowski, A. O. 2013. Integrated control of potato pathogens through seed potato certification and provision of clean seed potatoes. Plant Dis. 97:1268-1280.

Fuglie, K. O., Zhang, L., Salazar, L. F., and Walker, T. S. 1999. Economic impact of virus-free sweetpotato planting material in Shandong Province, China. https://pdf.usaid.gov/pdf_docs/PNACK412.pdf

Funke, C. N., Nikoleva, O. V., Green, K. J., Tran, L. T., Chikh-Ali, M., QuinteroFerrer, A., Cating, R. A., Frost, K. E., Hamm, P. B., Olsen, N., Pavek, M. J., Gray, S. M., Crosslin, J. M., and Karasev, A. V. 2017. Strain-specific resistance to potato virus $Y$ (PVY) in potato and its effect on the relative abundance of PVY strains in commercial potato fields. Plant Dis. 101:20-28.

German, T. L. 2001. Potato virus Y. Pages 69-71 in: Compendium of Potato Diseases, 2nd Ed. W. R. Stevenson, R. Loria, G. D. Franc, and D. P. Weingartner, eds. American Phytopathological Society, St. Paul, MN.

Gray, S. M., De Boer, S. H., Lorenzen, J. H., Karasev, A. V., Whitworth, J., Nolte, P., Singh, R., Bouche, A., and Xu, H. 2010. Potato virus Y, an evolving concern for potato crops in the United States and Canada. Plant Dis. 94:1384-1397.

Green, K. J., Brown, C. J., Gray, S. M., and Karasev, A. V. 2017. Phylogenetic study of recombinant strains of potato virus Y. Virology 507:40-52.

Guenthner, J. F., Plissey, E. S., Levi, A. E., and Makus, L. D. 1991. The impact of the Mandatory Seed Law on Maine potato acreage, yield, and price. Am. Potato J. 68:381-390.
Hane, D., and Hamm, P. 1999. Effects of seedborne potato virus Y infection in two potato cultivars expressing mild disease symptoms. Plant Dis. 83: 43-45.

Horton, D. E., Kim, Y. C., Hahn, B. H., Kim, K. K., Mok, I. G., Lee, B. N., and Kim, D. M. 1988. Potato research and development in the Republic of Korea: Organization, impact, and issues. Lima: International Potato Center in collaboration with Republic of Korea, Ministry of Agriculture, Forestry, and Fisheries, Rural Development Administration. https://books.google.com/ books?id=qnEJjfoWuR0C

Idaho Crop Improvement Association. 2016. Policies and procedures of certification for seed potatoes in Idaho. https://docplayer.net/56571552-Idaho-crop-improvementassociation-inc-policies-and-procedures-of-certification-for-seed-potatoes-inidaho-part-i-general-information.html

Idaho Office of the Administrative Rules Coordinator. 2012. Idapa 02.06.39 Idaho minimum seed potato standards. https://adminrules.idaho.gov/rules/2012/02/ 0639.pdf

Ivanov, K. I., Eskelin, K., Lõhmus, A., and Mäkinen, K. 2014. Molecular and cellular mechanisms underlying potyvirus infection. J. Gen. Virol. 95: 1415-1429.

Karasev, A. V., and Gray, S. M. 2013. Continuous and emerging challenges of potato virus $\mathrm{Y}$ in potato. Annu. Rev. Phytopathol. 51:571-586.

MacKenzie, T. D. B., Arju, I., Gallagher, A., Nie, X., and Singh, M. 2018a. Evidence of potato virus $\mathrm{Y}$ spread through post-emergence management practices in commercial potato fields. Am. J. Potato Res. 95:720-728.

MacKenzie, T. D. B., Fageria, M. S., Nie, X., and Singh, M. 2014. Effects of crop management practices on current-season spread of potato virus Y. Plant Dis. 98: 213-222.

MacKenzie, T. D. B., Lavoie, J., Nie, X., and Singh, M. 2018b. Differential spread of potato virus Y (PVY) strains O, N:O and NTN in the field: Implications for the rise of recombinant PVY strains in New Brunswick, Canada. Am. J. Potato Res. 95:301-310.

Marsh, T., Huffaker, R., and Long, G. 2000. Optimal control of vector-virus-plant interactions: The case of potato leafroll virus net necrosis. Am. J. Agric. Econ. 82:556-569.

Mello, A. F. S., Olarte, R. A., Gray, S. M., and Perry, K. L. 2011. Transmission efficiency of potato virus $\mathrm{Y}$ strains PVY-O and $\mathrm{PVY}^{\mathrm{N}-\mathrm{Wi}}$ by five aphid species. Plant Dis. 95:1279-1283.

Montana State University Seed Potato Certification Program. 2014. Montana State University rules and regulations for certification of Montana seed potatoes. http://www.montanaspud.org/documents/rules/sec1-2014\% 20\%20rulres.pdf

Moury, B., Fabre, F., and Senoussi, R. 2007. Estimation of the number of virus particles transmitted by an insect vector. Proc. Natl. Acad. Sci. 104: 17891-17896.

National Potato Council. 2017. Potato utilization, United States, 2013-2015. https://nationalpotatocouncil.org/files/4315/0030/7222/Potato_utiliz_U.S..pdf

Nolte, P., Alvarez, J. P., and Whitworth, J. L. 2009. Potato virus Y management for the seed potato producer. http://www.extension.uidaho.edu/publishing/pdf/CIS/ CIS1165.pdf

Nolte, P., Whitworth, J. L., Thorton, M. K., and McIntosh, C. S. 2004. Effect of seedborne potato virus $\mathrm{Y}$ on performance of Russet Burbank, Russet Norkotah and Shepody potatoes. Plant Dis. 88:248-252.

Oregon Seed Certification Service. 2016. Oregon potato seed certification service. https://seedcert.oregonstate.edu/crop-information/potatoes

Orsini, N., and Bottai, M. 2011. Logistic quantile regression in Stata. Stata J. 11 327-344.

Schramm, S., Frost, K., Charkowski, A., Gray, S., Crockford, A., and Groves, R. L. 2011. Management of potato virus Y (PVY) in Wisconsin seed potato production. https://cdn.shopify.com/s/files/1/0145/8808/4272/files/A3951.pdf

USDA Economics, Statistics, and Market Information System (ESMIS). 2017. Potatoes 2016 summary. https://downloads.usda.library.cornell.edu/usda-esmis/ files/fx719m44h/qj72p982m/qf85nf135/Pota-09-14-2017.pdf

USDA National Agricultural Statistics Service (NASS). 2016. Idaho annual statistical bulletin. https://www.nass.usda.gov/Statistics_by_State/Idaho/Publications/ Annual_Statistical_Bulletin/2016/ID_annual\%20bulletin\%202016.pdf

USDA National Agricultural Statistics Service (NASS). 2017. Idaho annual statistical bulletin. https://www.nass.usda.gov/Statistics_by_State/Idaho/Publications/Annual_ Statistical_Bulletin/2017/ID_annual\%20bulletin\%202017.pdf

USDA National Agricultural Statistics Service (NASS). 2018. Quickstats. https:// quickstats.nass.usda.gov/

USDA National Agricultural Statistics Service (NASS). 2019. Potatoes Annual Summary, various issues. Available from: https://usda.library.cornell.edu/ concern/publications/fx719m44h

Washington State Department of Agriculture. 2015. 2014-2015 Crop directory. https://www.waseedpotato.com/crop-directory

Whitworth, J. L., Nolte, P., McIntosh, C., and Davidson, R. 2006. Effect of potato virus $\mathrm{Y}$ on yield of three potato cultivars grown under different nitrogen levels. Plant Dis. 90:73-76. 